\title{
Plasma Polymerization of Pyrrole and Structures and Properties of the Polymerized Films
}

\author{
Yu IRIYAMA $^{\dagger}$ and Misaki HANAWA \\ Division of Interdisciplinary Sciences, Yamanashi University, \\ 4-4-37 Takeda, Kofu 400-8510, Japan
}

(Received December 5, 2000; Accepted January 25, 2001)

\begin{abstract}
Pyrrole was plasma polymerized on low-density polyethylene film. The plasma polymerized pyrrole film was analyzed with X-Ray photoelectron spectroscopy (XPS) and attenuated total reflection (ATR) FT-IR. A high level of $\mathrm{O}$ was found on the surface of the polymer film even though pyrrole monomer did not contain $\mathrm{O}$. In addition, $\mathrm{O}$ concentration increased gradually with storage time in ambient air. The increased $\mathrm{O}$ was found to come from water in air, not $\mathrm{O}_{2}$. However, the water was not simply absorbed on the surface. The gradual composition change of the surface was found due to hydrolysis of nitrile group, which had been formed in the plasma polymerization, with water in the air. KEY WORDS Plasma Polymerization / Pyrrole / O Content / X-Ray photoelectron Spectroscopy (XPS) / Attenuated Total Reflection FT-IR (ATR FT-IR)/
\end{abstract}

Electroconductive polymers, such as polyacetylene, poly ( $p$-phenylene), polythiophene, polypyrrole, etc., have been attracting interest for applications to electrical devices. Most electroconductive polymer films, however, have poor mechanical properties, because their structures mainly consist of conjugated double bonds. Among the electroconductive polymer films, polypyrrole has relatively good mechanical and thermal properties. Polypyrrole is usually polymerized electrochemically, but these properties as well as electroconductivity strongly depend on polymerization and doping conditions. The structure of electrochemically polymerized pyrrole is shown in Figure 1, which is arranged regularly to maintain conjugated system.

There are some studies on plasma polymerization of pyrrole. Plasma polymerization is a method to form very thin films in a dry system. In general, because applied plasma energy in the ordinary plasma polymerization is high enough, monomer structure does not always remain and cross-linking usually occurs. Therefore, it is little expected that the plasma polymerization forms materials with high crystallinity or high electroconductivity. There are, however, some reports of relatively high electroconductivity for plasma-polymerized pyrrole films. Plasma polymerization is a very simple dry system; therefore, if high electroconductive films can be formed by this method easily, it will be very useful.

For example, Cruz et al. obtained thin films of rf plasma-polymerized pyrrole. ${ }^{1}$ They found broken rings and many branching structures in the films. However, there was some conductivity: $10^{-12}-10^{-9} \mathrm{~S} \mathrm{~cm}^{-1}$ for the plasma-polymerized pyrrole and $10^{-9}-10^{-3} \mathrm{~S} \mathrm{~cm}^{-1}$

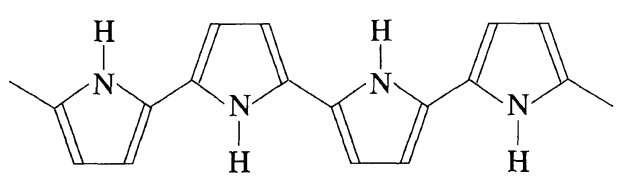

Figure 1. Structure of polypyrrole.

${ }^{\dagger}$ To whom all correspondence should be addressed. for the plasma-copolymerized pyrrole and iodine. The conductivity was also dependent on relative humidity.

Park et al. prepared thin film by rf plasma polymerization of pyrrole followed by thermal treatment. ${ }^{2}$ The film was found to have an electroconductivity of about $10^{-6}$ $\mathrm{S} \mathrm{cm}^{-1}$ with $p$-type semiconductor behavior.

In our research, although the preparation of electrically conducting thin films is not the primary objective, we have measured electroconductivity of the plasma polymerized pyrrole films and those after doping with $\mathrm{HClO}_{4}$ and $\mathrm{I}_{2}$. We have not, however, obtained conducting film so far, probably because the plasma energy density we used for the polymerization was so high as to cause substantial molecular rearrangement.

Aizawa et al. suggested the cleavage of pyrrole ring in rf plasma-polymerized pyrrole films because $\mathrm{C} \equiv \mathrm{N}$ bond was found in the FT-IR spectrum. ${ }^{3}$ Kojima et al. also suggested the formation of nitriles in $\mathrm{rf}$ plasmapolymerized pyrrole films from the results of pyrolysis of the film, but they also found alkylpyrroles in the analysis. ${ }^{4}$

Qui et al. used rf pulsed plasma for the polymerization of pyrrole. ${ }^{5}$ In the analysis of the polymerized film with FT-IR, they found larger absorption at around $750 \mathrm{~cm}^{-1}$ assigned to aromatic-ring $\mathrm{C}-\mathrm{H}$ stretching compared with that formed in continuous plasma: pulsed plasma is favored to retain monomer structures in the resulting film.

Van Ooij et al. polymerized pyrrole in dc plasma and obtained polymer films on the cathode. ${ }^{6}$ They analyzed the films with many kinds of analytical instrument and found no ring structure in the film but relatively high conductivity. They also found gradual structure change of the film after the polymerization with the absorption of oxygen.

This structural change is very interesting, which may be an intrinsic property for polypyrrole besides electroconductivity. Okuzaki et al. discovered quick and reversible bending of electropolymerized pyrrole film by a van der Waals absorption of water. ${ }^{7,8}$ Since the response is very fast, they demonstrated the film for the application to a chemomechanical rotor.

At our laboratory, we have found a quick roll-up of a 
polyethylene film coated with plasma-polymerized pyrrole in contact with ambient air. Such film can be obtained by plasma polymerization very easily in less than a minute. If this very fast physical reaction is reversible, its use for some sensor is expected. We also found composition change of the plasma-polymerized film over a long period of time. In this paper, we tried to reveal the structure of plasma polymerized pyrrole film and its structural change with mainly X-Ray photoelectron spectroscopy (XPS) and attenuated total reflection (ATR) FT-IR.

\section{EXPERIMENTAL}

\section{Materials}

Pyrrole, purchased from Wako Pure Chemical (special grade), was used as a monomer. As a substrate, lowdensity polyethylene (LDPE, $30-\mu \mathrm{m}$ thick) was used after rinsing with ethanol.

\section{Plasma Polymerization}

Plasma polymerization of pyrrole was carried out with plasma polymerization apparatus shown in Figure 2. Plasma is created between a pair of stainless steel electrodes (160-mm d., 60-mm gap) in the reactor. Three pieces of LDPE substrate $(40 \times 70 \mathrm{~mm})$ were placed on the bottom electrode. The reactor was evacuated with both a rotary vacuum pump and a mechanical booster for one hour for the pressure to be less than $1 \mathrm{~Pa}$, then the mechanical booster was turned off. Pyrrole was introduced into the reactor through a needle valve to be the pressure of $10 \mathrm{~Pa}$, of which flow rate was $2.5 \mathrm{sccm}$. The pressure of the system was monitored with an absolute pressure gauge (MKS Baratron 122AA). Capacitively coupled plasma was created with an $\mathrm{rf}$ generator of which power was supplied to the upper electrode. Plasma discharge power was set at $100 \mathrm{~W}$. Plasma polymerization time was varied from $15 \mathrm{~s}$ to $15 \mathrm{~min}$ for the measurement of XPS and $45 \mathrm{~min}$ for the measurement of ATR FT-IR. These plasma conditions were determined from our preliminary experiments in view of the maximizing O-absorbing ability of the resulting film. After the polymerization, we purged dry nitrogen, and put the samples into desiccator if necessary.

\section{Surface Analysis}

Surfaces of the plasma polymerized pyrrole films were

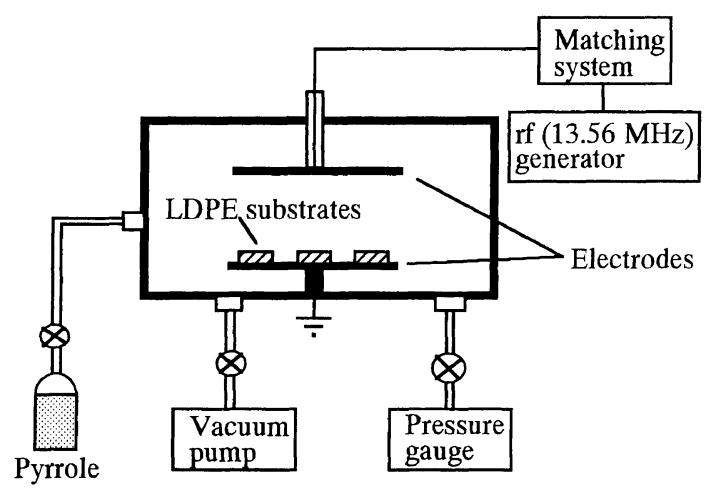

Figure 2. Schematic illustration of apparatus for the plasma polymerization of pyrrole. analyzed with XPS and ATR FT-IR. Surface chemical compositions of the films were investigated with XPS (Shimadzu ESCA-750). Operation conditions of XPS were as follows: X-Ray source, $\mathrm{Mg}-\mathrm{K} \alpha$; X-Ray gun, $10 \mathrm{kV}$ and $40 \mathrm{~mA}$; pass energy, $50 \mathrm{eV}$; and chamber pressure, $10^{-6}$ to $10^{-7} \mathrm{~Pa}$.

Structures of the films were investigated with ATR FT-IR (Shimadzu, FT-IR-8000). We deposited thick films (45-min polymerization) for the measurement of ATR FT-IR in order to obtain larger absorption signals.

Deposition rate and total thickness during the plasma polymerization of pyrrole were monitored with a deposition monitor (Leybold Inficon, XTM/2) that had a quartz oscillator and gold-coated sensor.

\section{RESULTS AND DISCUSSION}

When plasma polymerized pyrrole sample (on LDPE film) was taken out to ambient air, the film rolled up to be like a thin straw in a fraction of a second with the plasma polymer film outside. This phenomenon is thought due to the absorption of water in air. If so, we thought that a relatively high concentration of $O$ could be found on the surface, and analyses with XPS and ATR FT-IR would be suitable.

In XPS analysis of plasma polymerized pyrrole film on LDPE film, $\mathrm{O}$ was found about $3 \%$ just after the polymerization. In general, surfaces of any solid materials contain certain amounts of $\mathrm{O}$, but $3 \%$ for the materials that are supposed to contain no oxygen is not low. In fact, untreated LDPE film has only $0.5 \% \mathrm{O}$ content on the surface. Since pyrrole monomer contains no oxygen, it is natural to consider that water was absorbed when the reactor was opened to air after the polymerization. For XPS measurement, we tried to work promptly, but we took a few minutes to put the samples into the XPS chamber. During that time, the samples were exposed to air and believed to absorb water. However, taking into the measuring condition of XPS (high vacuum), it is not natural to consider that water was absorbed just physically. And what was more interesting, the surface composition was found to change gradually with storage time in air after the polymerization.

Figure 3 shows atomic percents of $\mathrm{C}, \mathrm{N}$, and $\mathrm{O}$ on the surface of the film vs. storage time in air up to four

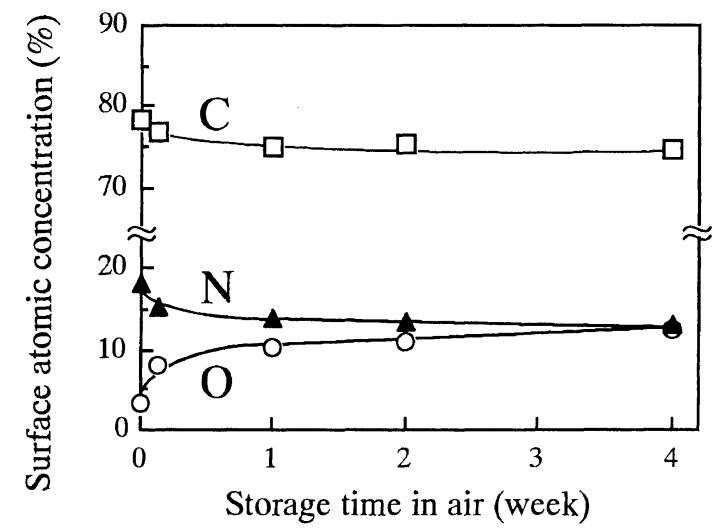

Figure 3. Change of the surface atomic concentration of the plasma-polymerized pyrrole film with storage time in air. 
weeks. The polymerization time of this sample was 5 min. According to the measurement by the deposition monitor, the deposition rate was $16 \mathrm{~nm} \mathrm{~min} \operatorname{mon}^{-1}$ and the total thickness was $80 \mathrm{~nm}$. Adhesiveness of the film on LDPE was good enough so that we could not peel it off with adhesive tape, while it was easily peeled off when deposited on a side glass.

In this figure, $\mathrm{O}$ increases while $\mathrm{C}$ and $\mathrm{N}$ decrease. This tendency of the surface composition change was observed even after four weeks. The data of atomic percent just after the polymerization and one day and one, two, and four weeks after storage in air are summarized in Table I. Although the major component is $\mathrm{C}$, the decrements of $\mathrm{C}$ and $\mathrm{N}$ in percent are almost the same, which means that some $\mathrm{N}$ must have been removed preferentially from the surface. Therefore, the increase of $\mathrm{O}$ might not be the result of the simple absorption of water. Concerning $\mathrm{O}$, just after the polymerization, about $3 \%$ of $\mathrm{O}$ was found, and $\mathrm{O}$ concentration increased gradually and reached $8 \%$ after $24 \mathrm{~h}$ and $12 \%$ after four weeks. If this increase comes from the absorption of water, this tremendously slow sensitivity is difficult to be understood. Therefore, some kind of slow reaction may be taking place on the surface with $\mathrm{H}_{2} \mathrm{O}$ or $\mathrm{O}_{2}$. It was also found that the plasma polymerization time had little dependence on the surface composition change, and all plasma-polymerized samples with different polymerization times showed very similar profiles as shown in Figure 3.

Since the plasma polymerization time could not be a factor for the increase rate or the total increment of $\mathrm{O}$ on the surface, we examined how little plasma polymerization time required to attain the $\mathrm{O}$-absorbing ability. Figure 4 shows the surface concentration of $O$ on the sample prepared at various polymerization times after 24-h storage in air. There is basically no dependence of the polymerization time on the surface concentration of $\mathrm{O}$, or the films with shorter polymerization time rather have higher $\mathrm{O}$ concentration. Even for the film obtained in 15-s polymerization, of which thickness was merely 4 $\mathrm{nm}$, the concentration of $\mathrm{O}$ was as high as $9 \%$. Fifteen seconds are the minimum time to create stable plasma; thus it could be shorter than that for the film to acquire the O-absorbing ability. It may be questionable whether such very thin film really had the $\mathrm{O}$-absorbing ability, or absorbed pyrrole monomer assisted. So, we conducted XPS measurement of a sample prepared in the same procedure (same evacuation and same monomer flow) without plasma. In the sample, pyrrole monomer might have been absorbed on the LDPE film, but the surface concentration of $\mathrm{O}$ was very low that was in the same level for untreated LDPE. Even in a short period, therefore, plasma polymerization was found to proceed and the very thin plasma-polymerized film was found to have the $\mathrm{O}$-absorbing ability.

Now we know the increasing $\mathrm{O}$ comes from water in air whatever the mechanism is. So we tried to presume the mechanism: it is simple absorption or some kind of chemical reaction takes part in.

We stored the samples in an ordinary desiccator and a vacuum desiccator and compared the composition change. In the ordinary desiccator, water (humidity) is eliminated, while in the vacuum desiccator, both water and oxygen $\left(\mathrm{O}_{2}\right)$ are eliminated. In Figure 5, surface concentrations of $\mathrm{O}$ of the samples are compared after storage in air and in the desiccators. O content increased rapidly for the sample stored in air, but slightly for those stored in both the desiccators. Theoretically, there should be no increase of $O$ content if the samples were stored in the vacuum desiccator, but this slight increase occurs during the replacement between the desiccator and the XPS chamber. Anyhow, the increment of $\mathrm{O}$ was

Table I. Atomic percent of the surface of plasma-polymerized pyrrole film after various strage times in air

\begin{tabular}{ccccccc}
\hline & \multirow{2}{*}{$\begin{array}{c}\text { Uncoated } \\
\text { LDPE }\end{array}$} & \multicolumn{5}{c}{ Plasma-Polymerized pyrrole } \\
\cline { 3 - 7 } & & Immediately after & 1 Day & 1 Week & 2 Weeks & 4 Weeks \\
\hline $\mathrm{C}$ & 95.5 & 78.5 & 76.7 & 75.1 & 75.4 & 74.7 \\
$\mathrm{~N}$ & 0 & 18.2 & 15.4 & 14.8 & 13.5 & 13.0 \\
$\mathrm{O}$ & 0.5 & 3.3 & 7.9 & 10.1 & 11.1 & 12.4 \\
\hline
\end{tabular}

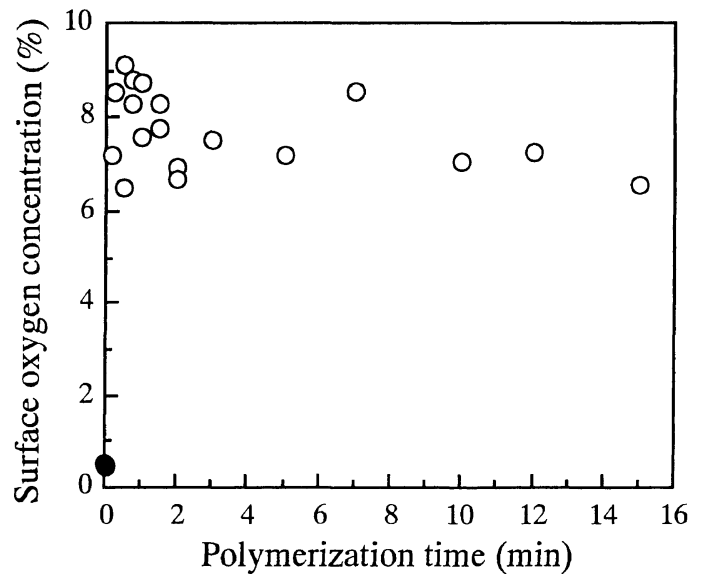

Figure 4. Dependence of surface oxygen concentration of the plasma-polymerized pyrrole film on the polymerization time.

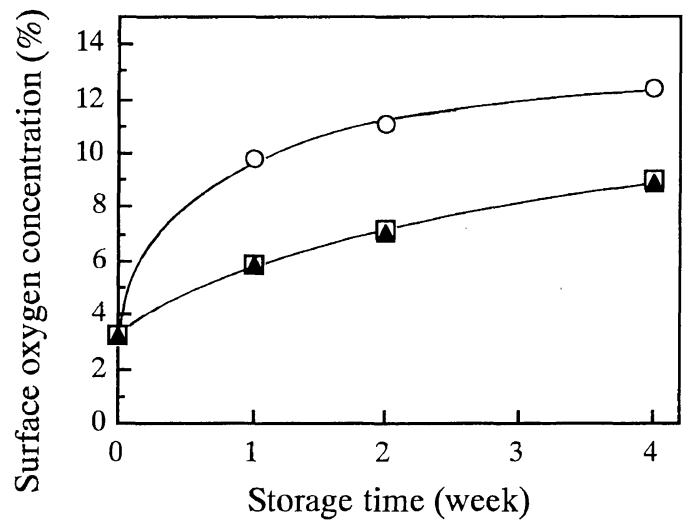

Figure 5. Change of surface oxygen concentration of the plasmapolymerized pyrrole films stored in air $(\bigcirc)$, ordinary desiccator (A), and vacuum desiccator $(\square)$. 


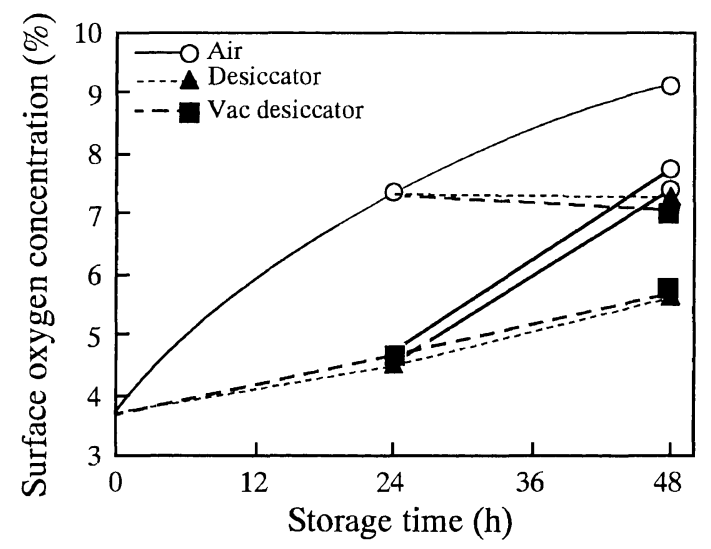

Figure 6. Change of surface oxygen concentration of the plasmapolymerized pyrrole films with change in storage conditions.

reduced considerably when the samples were stored in the desiccators, and there is little difference between the ordinary desiccator and the vacuum desiccator. Therefore, the increase of $\mathrm{O}$ concentration was found due to water (humidity) in air. In general, it is said that plasma polymerized or treated solid surfaces contain a great number of radicals that are susceptible to react with $\mathrm{O}_{2}$ in air. That may be the reason for the small increase in samples stored in the desiccators, but the gradual increase is not believed due to $\mathrm{O}_{2}$.

Next, we examined $\mathrm{O}$ concentration on changing storing conditions. We put the samples in air on the first day, then into the desiccator on the second day, or vice versa. The results are shown in Figure 6. When the sample is stored in air, $\mathrm{O}$ monotonously increases. After the sample was put into the desiccators on the second day, however, $\mathrm{O}$ did not increase or rather decreased. On the other hand, when the sample was put into the desiccators, $\mathrm{O}$ increased very slightly. When put into the air on the second day, however, $\mathrm{O}$ showed a rapid increase. It is very interesting to state that the $\mathrm{O}$ concentration is almost the same for the samples stored in air and the desiccator for one day each whatever the order was. Also, there is almost no difference between the ordinary desiccator and vacuum desiccator, because the increase of $\mathrm{O}$ is due to water (humidity) in air as we stated earlier.

For more detailed chemical information on the surface, we analyzed the samples with ATR FT-IR that measures only the surface of samples. Figures $7 \mathrm{a}$ and $7 \mathrm{~b}$ show ATR FT-IR spectra of uncoated LDPE film and plasma-polymerized pyrrole on LDPE film, respectively. For good resolution in this analysis, we prepared thick layers with 45-min polymerization, of which thickness was about $730 \mathrm{~nm}$. However, they were not thick enough so that many sharp signals originated from LDPE are observed. In the spectrum of uncoated LDPE film (Figure 7a), strong peaks were found at 2910, 2840, 1370, and $720 \mathrm{~cm}^{-1}$, which were assigned to stretchings and bendings of methyl and methylene groups of LDPE. In the spectrum of plasma-polymerized pyrrole on LDPE film (Figure 7b), a broad peak at $1550-1700 \mathrm{~cm}^{-1}$, a small but sharp peak at $2200 \mathrm{~cm}^{-1}$, and some small and broad peaks at many places newly appeared: the first peak was assigned to the mixture of $\mathrm{C}=\mathrm{N}, \mathrm{C}=\mathrm{C}$, and $\mathrm{C}=\mathrm{O}$ stretchings and $\mathrm{N}-\mathrm{H}$ bending, while the second

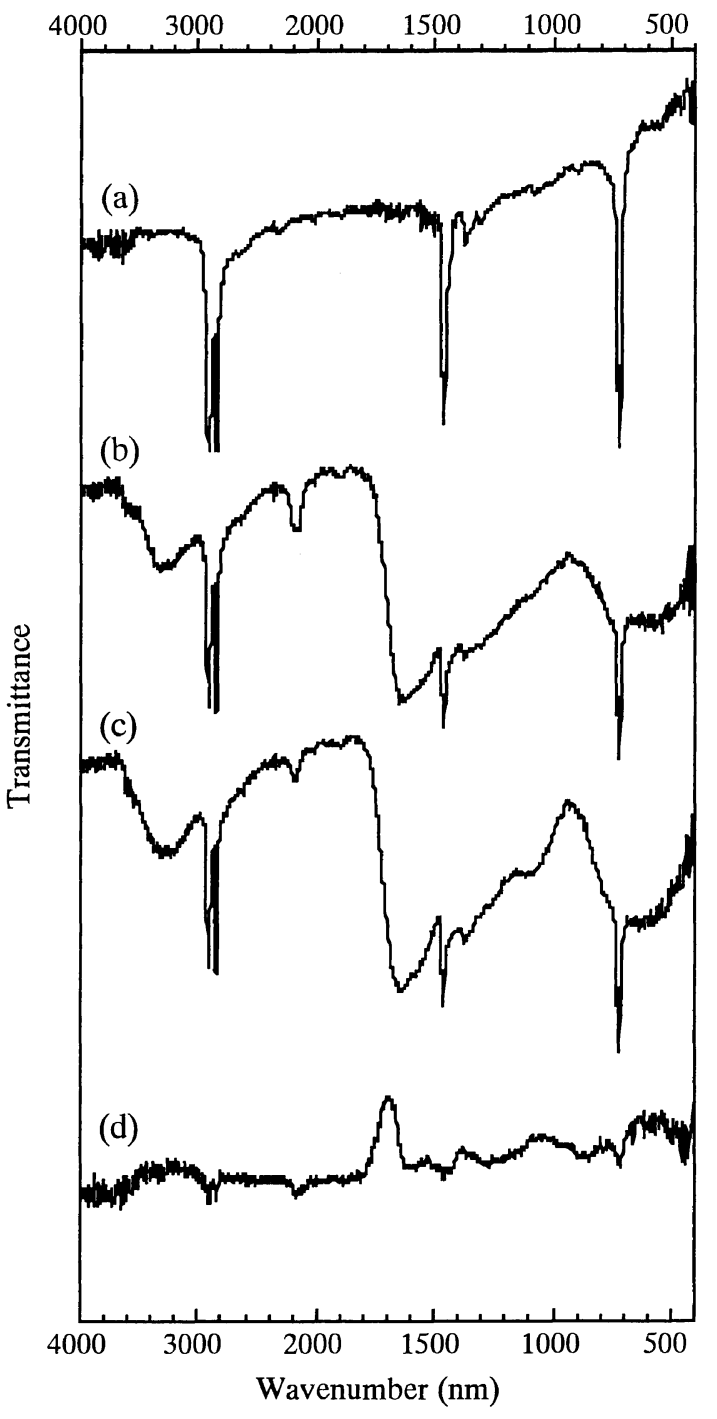

Figure 7. ATR FT-IR spectra of (a) uncoated LDPE film, (b) plasma-polymerized pyrrole film on LDPE film, (c) plasmapolymerized pyrrole film on LDPE film after four-week storage in the air, and (d) b-c (difference spectrum).

peak $\mathrm{C} \equiv \mathrm{N}$ stretching. For the first peak $(1550-1700$ $\mathrm{cm}^{-1}$ ), since pyrrole monomer has $\mathrm{C}=\mathrm{C}$ and $\mathrm{N}-\mathrm{H}$ bonds, the monomer structure could have been retained, but this great intensity strongly suggests the presence of $\mathrm{C}=\mathrm{O}$ bond. Although $\mathrm{O}$ is not included in the system, a very quick reaction is believed to take place when the sample contacted with ambient air. The second peak $\left(\mathrm{C} \equiv \mathrm{N}\right.$ bond at $2200 \mathrm{~cm}^{-1}$ ), which cannot be seen in the monomer, is characteristic absorption for the plasma polymer of pyrrole. From the spectrum, it is obvious that the pyrrole ring has been decomposed to some extent, though it is difficult to estimate the degree of the decomposition.

As $\mathrm{O}$ concentration gradually increased with storage time in air, the ATR FT-IR spectrum also changed gradually. Figure 7c shows the ATR FT-IR spectrum of the film after stored for four weeks in air. The peak at $2200 \mathrm{~cm}^{-1}$ became smaller and the one around 1700 $\mathrm{cm}^{-1}$ became broader. In order to clarify the changes in the IR spectra, we took the difference spectrum of them. Figure $7 \mathrm{~d}$ is the difference spectrum: the spectrum of 4- 
week storage was subtracted from that of immediately after the plasma polymerization. The peaks downward indicate increase and those upward indicate decrease during the four weeks. In the difference spectrum, it is clear that the peak at $2200 \mathrm{~cm}^{-1}$ decreased and a very sharp peak at $1720 \mathrm{~cm}^{-1}$ increased.

From the results of XPS and ATR FT-IR, we propose the following reaction mechanism on the surface of the plasma-polymerized pyrrole film in the ambient air.

Nitrile group, which is very active, is formed in the plasma polymerization. With water in air, the nitrile group is hydrolyzed to craboxylic acid and $\mathrm{N}$ was removed as ammonia. In this process, the $\mathrm{O}$ concentration (measured with XPS) and IR absorption at $1720 \mathrm{~cm}^{-1}$ increase, while $\mathrm{N}$ concentration and IR absorption at $2200 \mathrm{~cm}^{-1}$ decrease. This hydrolysis reaction may take place easily in a liquid phase with catalysis, but the reaction on the solid surface without catalysis may proceed slowly. This reaction is not the exclusive reaction taken place on the surface, but this reaction is very characteristic and may be very important.

\section{CONCLUSIONS}

Surface concentration of $\mathrm{O}$ on the plasma polymerized pyrrole films increased rapidly when stored in ambient air. The increase of $\mathrm{O}$ concentration was found due to water (humidity) in air. O-absorbing ability was found on the plasma polymer film polymerized for only $15 \mathrm{~s}$. The composition change of the plasma polymer film was slow but continued even after 4 weeks. From the results of XPS and ATR FT-IR, one of the characteristic reaction mechanisms was assumed to be the hydrolysis of nitrile group, which had been formed in the plasma polymerization, in air to be carboxylic acid with the removal of ammonia.

\section{REFERENCES}

1. G. J. Cruz, J. Morales, and R. Olayo, Thin Solid Films, 342, 119 (1999).

2. S. Y. Park, K. P. Lee, D. H. Choi, N. Kim, and S. K. Song, Mol. Cryst. Liq. Cryst., 247, 321 (1994).

3. H. Aizawa, M. Tazaki, and T. Homma, Kobunshi Ronbunshu, 53, 275 (1996). (in Japanese).

4. T. Kojima, H. Takaku, Y. Urata, and K. Gotoh, J. Appl. Polym. Sci., 48, 1395 (1993).

5. H. Qiu, F. S. Sanchez-Estrada, and R. B. Timmons, J. Photopolym. Sci. Technol., 13, 29 (2000).

6. W. J. van Ooij, S. Eufinger, and T. H. Ridgway, Plasmas Polym., 1, 229 (1996).

7. H. Okuzaki and T. Kunugi, J. Polym Sci., Part B: Polym. Phys., 34, 1747 (1996).

8. H. Okuzaki and T. Kunugi, J. Appl. Polym Sci., 64, 383 (1997). 